\title{
PHENOTYPIC DISSIMILARITIES AMONG INBREDS OF MAIZE (Zea Mays L.)
}

\author{
S. Subedi ${ }^{1}$, B. Paudel ${ }^{2}$ and B. Bhandari ${ }^{3}$ \\ Institute of Agriculture and Animal Science (IAAS), Lamjung Campus, Sundarbazar, Trivhuwan University, Nepal
}

Corresponding author's email: subedisangita325@gmail.com

\begin{abstract}
For development of single cross hybrids in maize, developed inbreds must be evaluated for the determination of highly heterotic inbred combination (HIC). One of the best methodologies for determination of heterotic inbred combination can be multivariate analysis (MVA) or scales of phenotypic distance or dissimilarities or cluster diagram. For it, inbred must be observed for useful trait measurements. Accordingly, an experimental evaluation was conducted including promising 55 inbred lines of winter maize planting on Sep 3, 2015 at National Maize Research Program Rampur, Chitwan Nepal (NMRP/NARC). The distant inbred lines were determined through MVA. Single plot research technique was done where each inbred line was provided with 2 rows of 20 plants each. Data were taken for fifteen traits. By the use of MINITAB software, the data was analysed. Graphics of principle component analysis (PCA) cluster diagram (CD or dendogram) were constructed and phenotypic dissimilarities are examined.The distant inbreds RML-8, RML-88, RML-13, RML-103, RML-89, RML-102, RML-11, RML-17, RML-83,RML-98,RML-85,RML-86,RML-94 and RML-28 could be crossed with RML-75,RML-6,RML-68,RML-36 and RML-32 which could be used as tester inbred for heterotic hybrid combination. Similarly, RML-98, RML-85, RML-86, RML-94 and RML28 could be crossed with RML-24, RML-96 and RML-99. Though distant inbred, RML-104 had less ASI but it wasn't feasible to use for crossing due to higher anthesis tasseling interval.
\end{abstract}

Keywords: Correlation; Dendrogram; Maize inbred lines; Multivariate analysis; Traits

Abbreviations: HSK CVR-Husk cover; ERS/PLANT-Ears per plant; TSSCOL-Tassel color; SILKCOL-Silk color; TSS TPTassel type; TSS SZ-Tassel size; LVS BE-Leaves below ear; LVS AE-Leaves above ear; STM CR-Stem circumference; INT ND-Internode length; PLT HT-Plant height

\section{Introduction}

Maize (Zea mays L.) is one of the most important cereal crops cultivated worldwide, belonging to family graminaceae. Being staple food crops, it is not only important for human consumption but it is also used as feed for animals. It also provides raw materials for manufacture of many industrial products from food processing to manufacturing of ethanol. It has leading position both in case of production and productivity. Maize is ranked in second position after rice in terms of area and production with the productivity of $2.458 \mathrm{t} / \mathrm{ha}$. Similarly, the area under production in Chitwan is 9750 ha, with $29250 \mathrm{mt}$ production and productivity $3000 \mathrm{~kg} / \mathrm{ha}$ (MoAD 2014). The demand is increasing for food; feed and industrial use (CDD, 2012). Maize has been the main source of food security for the developing country like ours, having $22.2 \%$ global hunger index. Globally, $80 \%$ of maize consumption is in animal feed. About $80 \%$ of egg production and $65 \%$ of the broiler production cost goes to the feed (CDD, 2012). In Nepal, The trend of feed demand is increasing at the rate of $11 \%$ per annum (CDD, 2012). There is a huge scope of expanding the poultry industry by 3 folds by the next $10 \mathrm{yrs}$, since the rate of poultry industries expansion is also $8.7 \%$ per annum (CDD 2012). Since, the productivity of maize in our country is much more less than that of developed countries we are still importing about 40 to $45 \%$ of maize (CDD, 2012). And in addition to higher price and uncontrollable quality, there is also the problem of unavailability on time of seeds for the farmers.

Thus, for the increased yield and proper availability of maize hybrids, maintenance and improvement of maize genotypes is the foremost requirement. For high production in maize, the precise selection of elite genotypes is very important for any area (Beiragi et al., 2010). Evaluation of important traits of maize lines is the primary factor for the improvement of maize. Information on the genetic distance and relatedness between the breeding materials of available germplasm is important for deciding which method will be applied in breeding programmes. The organisation of germplasm into genetically divergent groups is important for the implementation of the phenomenon of heterosis. This is crucial in the course of developing hybrid varieties with heterosis but it also can be applied in breeding of clones and open-pollinated varieties and synthetics (Chakuya, 2008). At the same time, two important questions arise: 1. How divergent are inbred lines from same and 
different heterotic groups and 2. Which criteria and biometric methods allow a dependable grouping of germplasm (Melchinger, 1999).Insufficient hybrid technology on our country had led to the less development of heterotic hybrid with higher yield. Information on morphological evaluation of inbred lines are lacking in Nepal. This study was conducted to examine inbreds for hybrid development and determine phenotypic distance among the fifty five inbreds of maize NMRS/NARC/Nepal evaluating flowering behavior, prolificacy and morphological traits of the inbreds which will be helpful to maize breeders for planning of heterotic inbred combination.

\section{Materials and Methods}

The experiment was conducted at the research farm of NMRP Rampur, Chitwan during winter, 2015 to evaluate the morphological traits. The geographical location as located by GPS was $27^{\circ} 40^{\prime} \mathrm{N}$ latitude, $84^{\circ} 19^{\prime} \mathrm{E}$ longitude at an altitude of $228 \mathrm{~m}$ above sea level. Single plot research technique with $60 \mathrm{~cm} * 25 \mathrm{~cm}$ spacing was done. Each inbred lines were provided with 2 rows of 20 plants each. Planting was done on $3^{\text {rd }}$ September, 2015. Two seeds per hill were planted. The intercultural operations were carried out as per the package of practice as per National Maize Research Program (NMRP) recommendation.

The sampling for each parameter was done through simple random sampling. Five plants were selected as sample from each inbred line. The parameters included days to $50 \%$ tasseling, days to $50 \%$ silking, days to $50 \%$ anthesis, anthesis- silking interval (ASI), tassel color, silk color, tassel type, tassel size, leaves below and above ear, stem circumference, internode length, husk cover, no of ear per plant and plant height. Days to $50 \%$ tasseling was recorded as number of days from planting to when $50 \%$ tassel appears. Days to $50 \%$ anthesis was recorded as the number of days from sowing to when $50 \%$ of the plants had shed pollen. Similarly, days to50\% silking, was recorded when silk had emerged on $50 \%$ of the plant. The stem circumference and internode length of the sample was measured for internode just above the upper cobb. Similarly, leaves above the upper ear and below that ear were recorded. The plant height per sample was taken by measuring from the ground level to the base of the tassel after milking stage. Data on husk cover was recorded before harvesting on a scale of 1 to 5 , where 1 and 5 represents poor and excellent respectively.

The traits like tassel color, tassel type and tassel size and silk color were assigned with code as per the standard of NMRP, Rampur chitwan for representing different colors (Table 1). These were recorded at the time of $50 \%$ tasseling, $50 \%$ silking respectively.

Among the collected data, tassel color, silk color, tassel type, tassel size, leaves below and above ear, stem circumference, internode length, husk cover, no of ear per plant and plant height were analyzed through the use of MINITAB Ver. 14 statistical software. Principal component analysis and cluster analysis were done to know the phenotypically dissimilar inbreds. The data was divided into 5 clusters in cluster analysis for dendrogram construction.

Table 1: Traits assigned with codes as per the standard of NMRP, Rampur, Nepal

\begin{tabular}{lll}
\hline Traits & Category & Code \\
\hline Tassel color & White & 1 \\
& Purple & 2 \\
& Semipurple & 3 \\
Silk color & White & 1 \\
& Purple & 2 \\
Tassel type & Open & 1 \\
& Semi-open & 2 \\
& Compact & 3 \\
Tassel size & Big & 1 \\
& Medium & 2 \\
& Small & 3 \\
\hline
\end{tabular}

\section{Results and Discussion}

The five different types of line bar (Fig. 1) represents five different clusters. The cluster analysis sequestrates genotypes into clusters which exhibit high homogeneity within a cluster and high heterogeneity between clusters (Jaynes et al., 2003). Cluster 1, 2, 3, 4, 5 included 45,4,1,3,2, inbreds respectively. The inbreds RML-8, RML-88, RML13, RML-103, RML-104, RML-98, RML-85, RML-89, RML-86, RML-102, RML-11, RML-17, RML-83, RML90, RML-94 were phenotypically distant from the inbreds RML-24, RML-96, RML-75, RML-6, RML-91, RML-68, RML-37, RML-36, RML-32 and RML-99. Same type of result was reported by Karanja et al., 2009.Maize inbred lines such as EM11-133, CML 395, CML 202, CML 442, CML 444, CML 312 were in one group while as EM12-210, CML208 and CML204 were in other group leaving OSU23i alone.

As a result of Principle Component Analysis (PCA), five principal components (PCs) out of eleven, had eigen value greater than 1 . These five eigen value contributed $70.1 \%$ of the total variability of eleven original variables among the inbreds observed. Chozin (2007) and Mujaju and Chakuya (2008) reported important contribution of the first PCs in total variability while studying different traits. Here, the principal component first (PC1) contributed maximum towards the variability $(20.8 \%)$ followed by PC2(17.5\%), PC3(12.8\%), PC4 (9.8\%) and PC5 (9.2\%). The trait TSS SZ showed considerable positive factor loadings on PC1 while ERS/PLANT (Ears per plant) and LVS AE showed negative loading score. The variability on PC2 was due to positive loading score of HSK CVR (Husk cover) and negative loading score of SILKCOL, STM CR and TSSCOL (Tassel color). The variation on PC3 was due to negative value of 
LVS AE, ERS/PLANT and INT ND. The PC4 was related to diversity among inbreds due to negative loading score of TSS TP. The variation on PC5 was due to negative loading score of SILKCOL and positive loading score of LVS AE

(Table 2 and 3 ).

\section{Dendrogram with Single Linkage and Euclidean Distance}

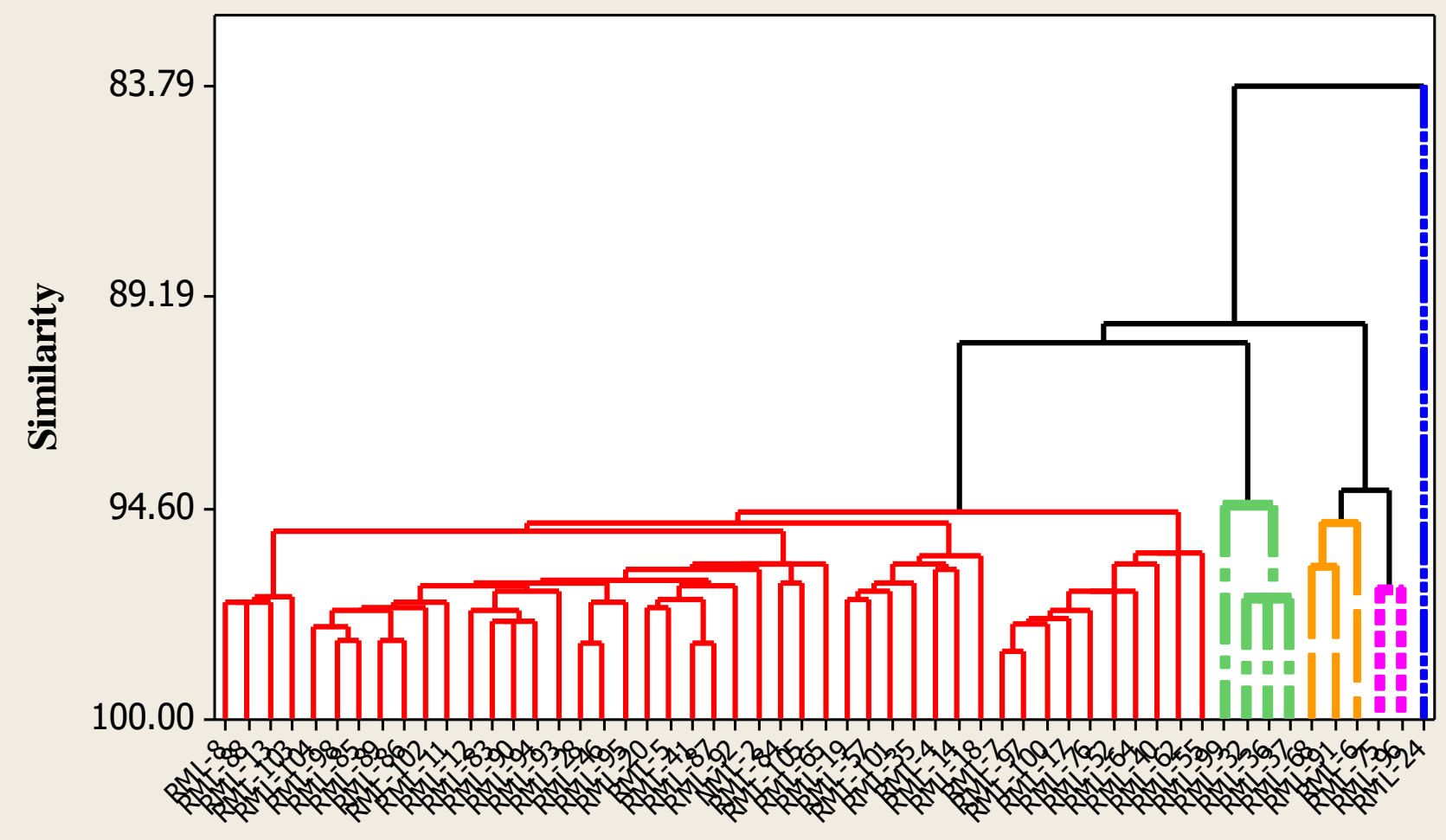

Inbreds

Fig.1: Dendrogram showing phenotypic distance among inbreds

Table 2: Details of principle component analysis through eigen analysis of the correlation matrix

\begin{tabular}{lllllll}
\hline Variable & PC1 & PC2 & PC3 & PC4 & PC5 & PC6 \\
\hline HSK CVR & -0.09 & $\underline{0.438}$ & -0.026 & 0.3 & -0.225 & -0.548 \\
ERS/PLANT & $\underline{-0.402}$ & -0.038 & 0.42 & -0.203 & 0.23 & 0.13 \\
TSSCOL & -0.276 & $\underline{-0.437}$ & 0 & -0.046 & -0.323 & -0.092 \\
SILKCOL & 0.04 & $\underline{-0.439}$ & -0.042 & -0.214 & $\underline{-0.639}$ & -0.063 \\
TSS TP & 0.184 & 0.122 & 0.351 & $\underline{-0.647}$ & 0.075 & -0.385 \\
TSS SZ & $\underline{0.334}$ & -0.26 & 0.229 & 0.238 & 0.227 & -0.486 \\
LVS BE & $\underline{-0.492}$ & 0.004 & 0.355 & -0.087 & 0.075 & -0.034 \\
LVS AE & -0.088 & -0.329 & $\underline{-0.446}$ & -0.1 & $\underline{0.524}$ & -0.003 \\
STM CR & -0.209 & $\underline{-0.414}$ & 0.186 & 0.42 & 0.157 & -0.284 \\
INT ND & -0.227 & 0.008 & $\underline{-0.508}$ & -0.367 & 0.096 & -0.447 \\
PLT HT & -0.51 & 0.248 & -0.168 & 0.129 & -0.112 & -0.069 \\
Eigen value & 2.2935 & 1.9199 & 1.408 & 1.0794 & 1.0127 & 0.8817 \\
Proportion & 0.208 & 0.175 & 0.128 & 0.098 & 0.092 & 0.08 \\
Cumulative & 0.208 & 0.383 & 0.511 & 0.609 & 0.701 & 0.781
\end{tabular}

HSK CVR-Husk cover; ERS/PLANT-Ears per plant; TSSCOL-Tassel color; SILKCOL-Silk color; TSS TP-Tassel type; TSS SZ-Tassel size; LVS BE-Leaves below ear; LVS AE-Leaves above ear; STM CR-Stem circumference; INT ND-Internode length; PLT HT-Plant height 
Table 3: Details of principle component analysis through eigen analysis of the correlation matrix

\begin{tabular}{|c|c|c|c|c|c|}
\hline Variable & PC7 & PC8 & PC9 & PC10 & PC11 \\
\hline HSK CVR & 0.446 & -0.046 & -0.205 & -0.098 & 0.325 \\
\hline ERS/PLANT & 0.212 & -0.284 & -0.626 & 0.053 & -0.17 \\
\hline TSSCOL & 0.447 & -0.382 & 0.461 & 0.199 & -0.142 \\
\hline SILKCOL & -0.149 & 0.171 & -0.398 & -0.348 & 0.122 \\
\hline TSS TP & 0.197 & 0.362 & 0.216 & -0.064 & -0.187 \\
\hline TSS SZ & -0.274 & -0.457 & 0.002 & -0.317 & -0.201 \\
\hline LVS BE & -0.353 & -0.043 & 0.326 & -0.222 & 0.579 \\
\hline LVS AE & 0.374 & 0.12 & -0.016 & -0.458 & 0.188 \\
\hline STM CR & -0.034 & 0.579 & -0.08 & 0.349 & -0.061 \\
\hline INT ND & -0.358 & -0.175 & -0.15 & 0.405 & 0.032 \\
\hline PLT HT & -0.159 & 0.145 & 0.115 & -0.421 & -0.616 \\
\hline Eigenvalue & 0.732 & 0.5402 & 0.4576 & 0.4032 & 0.2719 \\
\hline Proportion & 0.067 & 0.049 & 0.042 & 0.037 & 0.025 \\
\hline Cumulative & 0.848 & 0.897 & 0.939 & 0.975 & 1 \\
\hline
\end{tabular}

HSK CVR-Husk cover; ERS/PLANT-Ears per plant; TSSCOL-Tassel color; SILKCOL-Silk color; TSS TP-Tassel type; TSS SZ-Tassel size; LVS BE-Leaves below ear; LVS AE-Leaves above ear; STM CR-Stem circumference; INT ND-Internode length; PLT HT-Plant height

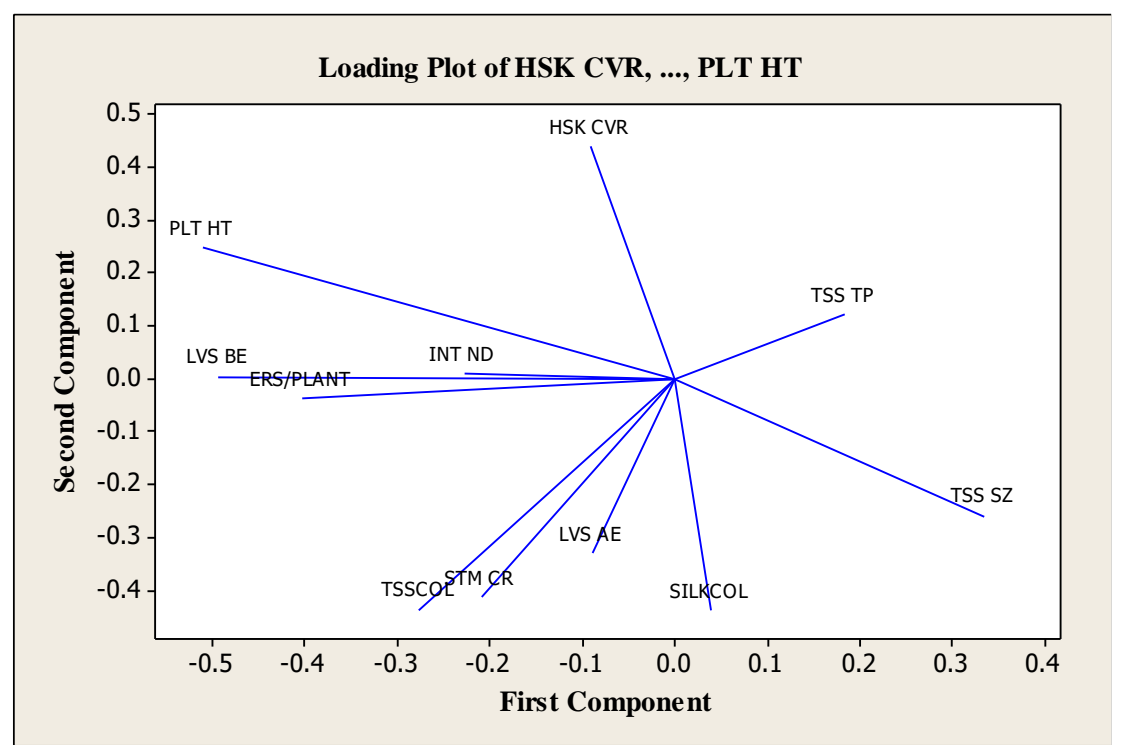

Fig. 2: Loading plot between PCs 1 and 2 showing contribution of various traits towards variability among inbreds

A PC loading plot in Fig. 2 showed that variables and genotypes are super imposed on the plot as vectors. The distance of each variable with respect to PC-1 and PC-2 showed the contribution of these variables in the variation of genotypes used. The loading plot (Fig. 2) showed that PLT HT, TSSCOL and LVS BE as a whole contributed maximum towards variability in maize germplasms.

The assessment of phenotypic traits of different maize genotypes are basically very simple and they are performed by a visual evaluation of individual plants or a group of plants and therefore it is not necessary to engage larger labour power. The massive use of PCs in agricultural studies has been allowed a simple application of the multivariate analysis that provides comprehending a simultaneous interrelation among three or more independent variables (de Galarreta, 2001). In plant breeding, such information can be useful for a comprehensive description of existing heterotic groups, as well as, for clustering inbreds of unknown genetic source and thereby defying a desirable tester.

Then, after the selection of distant inbreds, the inbreds were further checked for self-pollination with narrower anthesis silking interal and for synchronous flowering among distant inbreds. So that they can self-perpetuate. So that they can self-perpetuate. In Table 4 and 5, the distant inbreds were distinguished through underline and bold. 
Table 4: Data entry on flowering traits of maize inbred lines

\begin{tabular}{llllllllll}
\hline INBRED & TSS50 & ANT50 & SILK50 & ASI & INBRED & TSS50 & ANTH50 & SILK50 & ASI \\
\hline RML-8 & 52 & 56 & 57 & 1 & RML-98 & 49 & 52 & 54 & 2 \\
RML-99 & 50 & 52 & 53 & 1 & RML-102 & 51 & 54 & 56 & 2 \\
RML-103 & 50 & 54 & 55 & 1 & NML-2 & 48 & 51 & 54 & 3 \\
RML-104 & 50 & 56 & 57 & 1 & RML-5 & 52 & 54 & 57 & 3 \\
RML-12 & 56 & 58 & 60 & 2 & RML-7 & 49 & 52 & 55 & 3 \\
RML-19 & 54 & 57 & 59 & 2 & RML-11 & 55 & 57 & 60 & 3 \\
RML-20 & 51 & 55 & 57 & 2 & RML-13 & 49 & 53 & 56 & 3 \\
RML-57 & 50 & 53 & 55 & 2 & RML-17 & 52 & 55 & 58 & 3 \\
RML-65 & 48 & 51 & 53 & 2 & RML-18 & 53 & 56 & 59 & 3 \\
RML-83 & 51 & 55 & 57 & 2 & $\underline{\text { RML-36 }}$ & 54 & 57 & 60 & 3 \\
RML-88 & 51 & 55 & 57 & 2 & $\underline{\text { RML-24 }}$ & 48 & 51 & 54 & 3 \\
RML-89 & 51 & 55 & 57 & 2 & RML-28 & 49 & 52 & 55 & 3 \\
RML-90 & 50 & 54 & 56 & 2 & $\underline{\text { RML-32 }}$ & 51 & 54 & 57 & 3 \\
RML-41 & 50 & 53 & 56 & 3 & RML-40 & 46 & 49 & 3 & 52 \\
$\underline{\text { RML-36 }}$ & 54 & 57 & 60 & 3 & & & & & \\
\hline
\end{tabular}

RML-Rampur Maize Line; NML-National Maize Line

Table 5: Data entry on tassel and silk related traits of maize inbred lines

\begin{tabular}{llllllllll}
\hline INBRED & TSS50 & ANT50 & SILK50 & ASI & INBRED & TSS50 & ANTH50 & SILK50 & ASI \\
\hline RML-52 & 48 & 51 & 54 & 3 & RML-105 & 48 & 50 & 53 & 3 \\
RML-62 & 54 & 57 & 60 & 3 & RML-4 & 52 & 54 & 58 & 4 \\
RML-64 & 52 & 56 & 59 & 3 & $\underline{\text { RML-6 }}$ & 52 & 55 & 59 & 4 \\
$\underline{\text { RML-68 }}$ & 53 & 56 & 59 & 3 & RML-35 & 47 & 51 & 55 & 4 \\
$\underline{\text { RML-75 }}$ & 52 & 55 & 58 & 3 & RML-46 & 42 & 44 & 48 & 4 \\
RML-76 & 52 & 56 & 59 & 3 & RML-55 & 47 & 50 & 54 & 4 \\
RML-84 & 50 & 53 & 56 & 3 & RML-85 & 50 & 52 & 56 & 4 \\
$\underline{\text { RML-91 }}$ & 46 & 49 & 52 & 3 & RML-86 & 49 & 53 & 57 & 4 \\
RML-92 & 46 & 50 & 53 & 3 & RML-87 & 51 & 53 & 57 & 4 \\
RML-94 & 47 & 51 & 54 & 3 & RML-93 & 47 & 50 & 54 & 4 \\
$\underline{\text { RML-96 }}$ & 47 & 51 & 54 & 3 & RML-95 & 50 & 53 & 57 & 4 \\
RML-97 & 49 & 51 & 54 & 3 & RML-14 & 49 & 52 & 57 & 5 \\
RML-100 & 51 & 55 & 58 & 3 & $\underline{\text { RML-37 }}$ & 42 & 44 & 50 & 6 \\
RML-101 & 46 & 48 & 51 & 3 & & & & & \\
\hline
\end{tabular}

RML-Rampur Maize Line; NML-National Maize Line

Analyzing, anthesis silking interval, anthesis tasseling interval and flowering synchronization through phenotypically distant inbreds, the inbreds RML-8, RML88, RML-13, RML-103, RML-89, RML-102, RML-11, RML-17, RML-83,RML-98,RML-85,RML-86,RML-94 and RML-28 could be crossed with RML-75,RML-6,RML68,RML-36 and RML-32 which could be used as tester inbred for heterotic hybrid combination. Similarly, RML98, RML-85, RML-86, RML-94 and RML-28 can be crossed with RML-24, RML-96 and RML-99. Though distant inbred, RML-104 had less ASI but it wasn't feasible to use for crossing due to higher anthesis tasseling interval.Genetic diversity was also studied by Azad, 2012 to find out the more diverse inbred lines in maize which might be used in hybridization programme. Thirty maize inbred lines were grouped into six different clusters. 


\section{Conclusion}

Hence, combined effect of all alleles of 10 traits was observed to determine the longest linear distance. The inbreds with dissimilarity were obtained on five different clusters.The crosses involving parents/inbred lines from most divergent clusters were expected. Thus the distant inbreds with smaller anthesis siking interval and selfperpetuation among inbreds could be used as tester inbreds for heterotic inbred combination. And the hybrid with heterosis could be obtained in smaller number of crossing.

\section{Acknowledgement}

We are grateful to the professor Navraj Adhikari, Professor Lal Prashad Amagai and Balram Bhandari sir for their kind support and guidance throughout the research period. And we would also like to acknowledge National Maize Research Programme, Rampur Chitwan for providing me such a platform to carry out the research.

\section{References}

Ashofteh BM, Siahsar B, Khavari S, Golbashy M, Mehdi NN and Alizadeh A (2010) Effects of Genotype by Environment Interactions on Morphological Traits, Yield and Yield Components of New Grain Corn (Zea Mays L.) Varieties. Agroecology 2(1): 136-145.
CDD (2012). Annual Report: Maize Mission Programme.

Chozin M (2007) Characterization of sorghum accessions and choice of parents for hybridization. J. Akta Agr. Edisi Khusus 2: 227-232.

de Galarreta JR and Alvarez A (2007) Morphological classification of maize landraces from northern Spain. Genetic Resources and Crop Evolution 48(4): 391-400.

Jaynes DB, Kaspar TC, Colvin TS and James DE (2003) Cluster analysis of spatiotemporal com yield pattern in an Iowa field, J. Agron 95: 574-586.

Karanja J, Amugune NO, Ininda J, Kimatu JN and Danson JW (2009) Microsatellite analysis of the correlation between molecular and morphological traits in assorted maize inbreed lines. J. African Crop Science 17(3): 33-144.

Melchinger AE (1999) Genetic diversity and heterosis. The Genetic and Exploitation of Heterosis in Crop. ASACSSA-SSSA, 677 South Segoe Road, Madison, WI 53711, USA: 99-117.

MoAD (2014) Statistical information on Nepalese agriculture 2013/14

Mujaju C and Chakuva E (2008) Morphological variation of sorghum landrace accessions on-farm in semi-arid areas of Zimbabwe. Int. J. Botany 4: 376-382 